\title{
EDITORIAL
}

\section{Celso Furtado, centenário}

Com a aproximação de 2022 - quando abundarão os eventos e reflexões em torno à Semana de Arte Moderna e à Independência do Brasil -, é mais que bem-vindo um número da Revista do Instituto de Estudos Brasileiros dedicado a Celso Furtado, que foi um dos mais notáveis pensadores da vida brasileira. Nascido na Paraíba, em I920, sua formação e maturidade praticamente atravessaram o século $\mathrm{XX}$, conseguindo deixar um legado de independência crítica e de engajamento por uma sociedade mais justa que serve de inspiração para lidar com os anos sombrios que atualmente vivemos.

Como se sabe, sua maior contribuição se deu no campo da economia, sobretudo no que se refere ao entendimento estrutural da condição de subdesenvolvimento, que marca a posição dos países periféricos em relação ao capitalismo central. Em Formação econômica do Brasil, de I959, desenvolve de maneira ousada e criativa o método histórico-estrutural para compreender os vários momentos de inserção da economia brasileira no sistema internacional, realçando os constrangimentos e potencialidades colocados para uma sociedade marcada pela desigualdade.

Nessa obra e nas demais que lhe sucederam, sem deixar de apontar os mecanismos de subordinação econômica e política, Furtado destaca as potencialidades abertas ao presente. A ferramenta teórica de compreensão do subdesenvolvimento deve agir sobre o processo histórico no sentido da sua superação.

Furtado também é atento às desigualdades regionais, herdadas da monocultura exportadora, pois representam uma dificuldade suplementar no âmbito de qualquer planejamento econômico. Segundo ele, o "desenvolvimento da primeira metade do século $\mathrm{XX}$ apresenta-se basicamente como um processo de articulação das distintas regiões do país em um sistema com um mínimo de integração. [...] e na segunda [metade] poderá aguçar-se o temor de que o crescimento intenso de uma região é necessariamente a contrapartida da estagnação de outras" (FURTADO, I989, p. 236-237; p. 239). Para a superação dessas "disparidades regionais", torna-se fundamental uma visão estratégica de futuro, em que o 
planejamento comparece para a viabilização de um sistema econômico nacional autônomo.

A contribuição do autor, porém, extrapola em muito a tenacidade do economista para assumir as múltiplas facetas de historiador, sociólogo e geógrafo, capaz inclusive de colocar a cultura como dimensão constitutiva do desenvolvimento. Muito produtivo, escreveu dezenas de obras, dedicadas a diversos tópicos, sempre com o brilho de uma escrita clara, fluente e perspicaz, empenhada em coligar as ideias abstratas e gerais aos exemplos particulares e históricos. Como intelectual do seu tempo, entendia que a atividade do pensamento crítico devia estar comprometida com a ação objetiva, o que o levou a abraçar a carreira política, em momentos especiais de sua trajetória, sem se afastar do ideário emancipacionista.

Por isso mesmo, pode-se afirmar que Furtado é um pensador da brasilidade, conceito difícil de definir, mas que acena para uma particularidade histórica e social que deve ser compreendida, ou ao menos questionada. Pois, já que um país não é feito apenas de suas forças produtivas, deve-se levar em conta também o contingente humano que lhe empresta vivacidade e autenticidade. Portanto, é sob a condição de intérprete do Brasil que o nosso homenageado comparece nas páginas deste número da RIEB - antecipando temas e abordagens que certamente serão relembrados no ano que vem, por ocasião das comemorações da tríade de 22.

É importante destacar que este dossiê apenas existe graças à doação do arquivo e da biblioteca de Celso Furtado realizada por Rosa Freire d'Aguiar ao IEB no ano de 20I9. As fotos e os documentos que os acompanham fazem parte desse valioso acervo.

Desde então o IEB tem promovido um conjunto de atividades com o objetivo de contribuir para a divulgação e o debate em torno ao pensamento dessa grande figura brasileira. Nesse sentido, como parte das atividades do seu centenário, o IEB organizou uma sequência de podcasts ${ }^{\mathrm{I}}$, os IEBinários Celso Furtado² e um curso de pós-graduação sobre o seu método, trajetória e obra, além de ter estabelecido parcerias para a realização de seminários e publicações sobre Formação econômica do Brasil e a Superintendência do Desenvolvimento do Nordeste (Sudene). Essas iniciativas culminam agora neste dossiê, preparado de forma criteriosa por seus organizadores, que trataram de resgatar novos olhares sobre o intelectual a partir da dupla chave da transdisciplinaridade e contemporaneidade.

Fernando Paixão 3 , Inês Cordeiro Gouveia ${ }^{4}$, Luciana Suarez Galvão ${ }^{5}$

Editores

I Os podcasts I27 a I37, disponibilizados entre 9 e 26 de outubro de 2020 , podem ser acessados em: https:// anchor.fm/difusieb.

2 Os IEBinários Celso Furtado, realizados em 23 e 30 de novembro e 7 e I/4 de dezembro de 202I, estão disponíveis em: http://www.ieb.usp.br/iebinario.

3 Universidade de São Paulo (USP, São Paulo, SP, Brasil).

4 Universidade de São Paulo (USP, São Paulo, SP, Brasil).

5 Universidade de São Paulo (USP, São Paulo, SP, Brasil). 


\section{REFERÊNCIA}

FURTADO, Celso. Formação econômica do Brasil. 23. ed. São Paulo: Companhia Editora Nacional, I989.

SOBRE OS AUTORES

FERNANDO PAIXÃO é docente do Instituto de Estudos Brasileiros da Universidade de São Paulo (IEB/USP).

fernando.paixao@usp.br

https://orcid.org/oooo-000I-5I57-I506

INÊS GOUVEIA é docente do Instituto de Estudos Brasileiros da Universidade de São Paulo (IEB/USP). inescgouveia@usp.br https://orcid.org/oooo-0003-4783-9033

LUCIANA SUAREZ GALVÃO é docente do Instituto de Estudos Brasileiros da Universidade de São Paulo (IEB/USP).

lsgalvao@usp.br

https://orcid.org/0000-0003-I369-688X

Recebido em 5 de abril de 2021

Aprovado em 8 de abril de $202 I$

PAIXÃO, Fernando; GOUVEIA, Inês Cordeiro; GALVÃO, Luciana Suarez. Furtado, intérprete do Brasil. Revista do Instituto de Estudos Brasileiros, Brasil, n. 78, p. I3-I5, abr. $202 \mathrm{I}$.

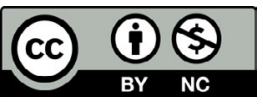

DOI: https://doi.org/Io.II606/issn.23I6-90IX.vIi78pI3-I5 